\title{
Which Ontology behind Narrative Ethics
}

\author{
Silvia Pierosara \\ University of Macerata
}

\begin{abstract}
This paper addresses the relationship between ontology and ethics, as outlined in Charles Taylor's essay "Ethics and Ontology,” problematizing it from a narrative ethics viewpoint. It attempts to overcome the "binary” dichotomy presented in Taylor's essay, insisting instead in favour of an approach that distances itself from both reductionist naturalism and ancient and medieval ontological models. The move towards narrative ethics is positioned in relation to an implicit ontology. Taylor recognizes that man’s way of life "consists of ways of sense making;" this human trait thus being an ontological presupposition, or precomprehension. Here, I suggest that this pre-narrative quality is in fact an ex ante projection of the work of meaning-making, arising ex post and, crucially, not universally attainable. If it were, it would be an unwarranted ontologization of features of human moral experience. Organizing the relationship between ontology and ethics within the perspective of narrative ethics does not mean doing away with the ontological dimension. Indeed, as this paper seeks to demonstrate, the ontological background of narrative ethics may be traced from a phenomenology of fragility, exposure, and interdependence. The definition of man as a self-interpreting animal should therefore be delineated in the sense of an endeavour; in this way, the individual can build up his own mediated relation with meaning, and, as a result, the practice of self-narrative becomes available to all.
\end{abstract}

Keywords: narrative ethics, weak ontology, self-interpretation, interdependence

\section{The Ontological Status of the Search for a Meaning}

Starting from suggestions made by Charles Taylor in his essay "Ethics and Ontology,” my contribution intends to problematize the relationship between ontology and ethics from the standpoint of narrative ethics, as addressed by Taylor himself, amongst others. The present contribution is divided into three parts. In this first part, I aim to go beyond the "binary" dichotomy in the relationship between ethics and ontology as presented in Taylor's essay. In other words, my hypothesis is that ethics requires an ontology that distances itself just as much from reductionist naturalism — which Taylor does not hesitate to criticize with solid argument—as it does from ancient and medieval ontological models. To a certain extent, both viewpoints redefine the space of uncertainty and diminish the importance of choice, ascribing its responsibility to nature or to our ontological and anthropological structure or make-up, as metaphysically certified and accepted. Equally, and conversely, both models diminish the optional nature of ethical choices: the former by invalidating them, the latter by suggesting man's exceptional nature to be "genetic," codified as a need to search for and construct meaning.

Taylor's first aim in "Ethics and Ontology" is to come to terms, once and for all, with naturalism: "I am

Silvia Pierosara, Ph.D. in Philosophy and Theory of the Human Sciences, Adjunct Professor of Moral Philosophy, Department of Humanities-Philosophy Section, University of Macerata, Italy; main research fields: Contemporary Narrative Ethics, Ethics of Recognition, Contemporary Critical Theory, Social Philosophy, and Hermeneutics. 
sorry to trouble a hard-won peace, but it seems to me that there remains an issue here. Some sources of the temptation to undercut the phenomenology of the moral life in the name of a post-Galilean 'naturalism' have been perhaps laid to rest, but others remain" (Taylor 2003, 314). "So even if we no longer aspire to reductive explanations, we still can balk at the full 'reality' of the intrinsically higher, in the name of a naturalistic, evolutionary account of the human animal and his life form” (Taylor 2003, 316).

What does it mean to say that the "intrinsically higher" is real? What if we admitted the reality of something "intrinsically higher?" Would we be allowed to consider our asymptotic attempt to interpret our emotions and feelings as a real, probably "natural" feature of human beings? Let us try to follow this path together with Charles Taylor and his brilliant essays "Self-interpreting Animals and Explanation and Practical Reason," in order to understand the ontological claims behind this ethical hypothesis and, hopefully, to make the distinction between naturalistic ontology and ontology tout court both possible and clear.

Let us start by noting that Charles Taylor had already come to grips with the relationship between ontology and ethics in 1959, when he wrote the article entitled, precisely, “Ontology.” In that essay, he pointed out that "it is clear that almost no one will want to refuse to admit that we can talk meaningfully of behaviour. But a problem seems to arise when we wish to make clear how it differs from, and is related to, e.g., events and processes in nature" (Taylor 1959, 129). He thus recognized that behaviour does have an ontological commitment and asked himself what kind of commitment this might be, trying to differentiate it from natural processes and, subsequently, from a naturalistic ontology. In this article, Taylor summed up some contemporary discussions regarding the relationship between ethics and ontology by saying that the ontological questions raised by human behaviour and the predicates used in order to grasp it are commonly classified as nonsense questions; but, he pointed out, they are nonsense questions only from the standpoint of scientific or ordinary language: “Our metaphysical craving for the real language remains unsatiated” (Taylor 1959, 141).

In Self-interpreting Animals, his starting point is neither ontology nor language; rather, he starts from a phenomenology of human emotions and feelings and tries to get back to their ontological presuppositions. There is an ontological presupposition behind emotions and feelings: Human beings are strong evaluators, provided that the expression "strong evaluators" means that human beings are those beings that cannot but interpret and articulate their emotions and feelings. This latter is not a contingent or extrinsic feature; it is rather the essence of man, of his ontological structure, which cannot but be grasped with language. Let us try to follow Taylor in his move from phenomenology to ontology. "Experiencing a given emotion involves experiencing our situation as bearing a certain import, where for the ascription of the import is not sufficient just that I feel this way, but rather the import gives the grounds or basis for the feeling. And that is why saying what an emotion is like involves making explicit the sense of the situation as we experience it” (Taylor 1985, 49).

Could we say that the import links moral phenomenology to ontology? Doesn't the fact that the import grounds our feelings mean that our feelings are to be grounded in an objective state of affairs or, perhaps, values? Of course it does, but only if we aim at describing imports in an objective way; as Taylor would probably reply. The nature of values is questioned here. According to Taylor, moral phenomenology tells us that import necessarily implies the independent reality of values, as far as we discover ourselves to be users of these values. Nevertheless, if we aim towards an objective account of moral experiences and shared values, from the subject's standpoint, we cannot help avoiding the naturalistic solution, according to which we are endowed with a natural capacity for value-perception. This objection is not completely addressed by Taylor, since his solution 
directly comes from a matter of moral sources, ultimately of belief. Moreover, analysing the question from the object's standpoint (the object here is the value), we must admit its existence independently of us. Rather, from Taylor's account, it could be pointed out that the reality of values is relational. In other words, values make sense to the extent that are relational "entities."

But according to Taylor's account of the import, ontology is called into question otherwise:

implicit in this import is a reference to the subject; because the import this situation bears is that it lays an obligation of strong kind on me-what we call a moral obligation or an obligation of charity. And a full understanding of what this means involves reference to the kind of being on whom this obligation is laid. The situation bears this import for me, in virtue of the kind of being I am; and this is a logical truth, internal to the meaning of the import. (Taylor 1985, 58)

Ontology does not disappear, rather it is claimed to be subject-sided: Moral obligations are grounded on the kind of beings we are; more deeply, defining imports means having to do with the definition of human beings. Only to the extent that we are human beings do we recognize moral obligations in situations that bear import for us as subjects.

Our subject-referring feeling attributes imports which cannot be reductively explained, but which involve reference to a subject who is aware of them. They are essentially imports for a subject... The sense of imports that they (the feelings) incorporate has been articulated into a picture of our moral predicament, according to which some goods are higher than others, while still others are false or illusory. And this is where it begins to make sense to speak of man as self-interpreting animal. (Taylor 1959, 63)

We are self-interpreting animals as far as we experience moral feelings and try to articulate them. It is precisely within this context that the notion of "strong evaluation" begins to make sense. Human beings are strong evaluators since they are able to split between lower order and higher order desires and motivations. Nevertheless, isn't the fact that the subject can recognize herself as a strong evaluator ultimately ascribable to her nature? Isn't it an ontological pre-understanding —one that shares its background, if not with naturalism, at least with the classical ontological pattern? Or, rather, how can this view exclude once and for all a naturalistic explanation? How can such a conclusion be avoided? Moreover, even when Taylor appeals to the intrinsically linguistic way of providing justifications for our emotion, there is no evidence that such intrinsic and innate qualities are due to its being "natural" in an ontological sense.

Two senses of ontology are here called into question: The first is the naturalistic one and it seems that the author cannot exclude this explanation; in another sense, if our attempt to make sense and articulate our feelings is structurally internal and essential to defining human beings, how can we save human freedom? Isn't it a form of automatism even if we define human beings as always already self-interpreting animals? Taylor's account of human beings as "self-interpreting animals" implies the inevitability of a recall of the linguistic nature of our moral reflection, which in turn implies the symbolic feature of human language. Ultimately, human beings are symbolic animals, but they are still animals.

Thus, for us language-animals our language is constitutive of our emotions, not just because de facto we have articulated some of them, but also de jure as the medium in which all our emotions, articulate and inarticulate, are experienced. Only a language-animal could have our emotions: and that means, inter alia, emotions which involve strong evaluations. (Taylor 1985, 74)

Yet, thanks to language and to our self-interpreting attitude, we are animals able to aspire to a "richer ontology." "In all lucidity, we cannot understand ourselves, or each other, cannot make sense of our lives or 
determine what to do, without accepting a richer ontology than naturalism allows, without thinking in terms of strong evaluation” (Taylor 1995, 39).

The "richer ontology" that Taylor refers to is not far from the classical teleological ontology. The problem arises when it comes to define such a "richer ontology," trying to enucleate some ontological or anthropological constants: "to the extent that one can call on human constants, these are much more difficult to arbitrate" (Taylor 1995, 50).

To sum up the outcomes of this first part, we can draw attention to the following statements:

(1) In order to define human nature, it is necessary to start from moral phenomenology;

(2) Moral phenomenology proves that human beings are human beings to the extent that they are able to distinguish, evaluate, and articulate their emotions and feelings by referring to values; their unavoidable ontological feature is their capacity for interpretation, their being always already strong evaluators;

(3) This assumption implies a number of questions concerning the ontological reality of values. Taylor, however, shifts his attention from the objectivity of values to the objectivity—meant as universality—of human practices of self-interpretation, or interpretation of moral imports that imply ontological commitments; such a shift leads to a sort of subject-sided ontology;

(4) Naturalism is not laid to rest, since according to Taylor's account, we are not definitely allowed to exclude the hypothesis that our being "self-interpreting animals" is a "natural" endowment and whether it is ultimately based on physiological grounds. Naturalism cannot be laid to rest, since it is a question of belief: Taylor wishes to go beyond the "immanent frame" by means of a renewed interpretation of belief; and even if for the sake of argument we grant that he has come to terms with naturalism, there is the suspicion he does so by appealing to a classical ontological and teleological pattern which ascribes to human nature the innate capacity for self-interpreting and strongly evaluating;

(5) However, we are allowed to affirm that what Taylor explicitly admits is an ontology that can be defined as a "weak ontology;” through an analysis of such a perspective, it is worth asking whether this ontology is able to come to terms both with naturalism and with classical ontology.

\section{Weak Ontology and the Move towards Narrative Ethics}

It is not by chance that in the last decade Taylor has moved back to ontology and he has pinpointed such a sort of "weak ontology;" this definition is not its own; it was coined by Stephen White in order to classify the ontologies which reject both anti-foundationalism and foundationalism; from Taylor's standpoint, we could associate the former to naturalism and the latter to the traditional metaphysical ontological framework, the two perspectives that he discussed in "Ethics and Ontology." Some of the views put forward in his article "The Weak Ontology Thesis" can be shared, and I would like to move to the second part of this talk trying to shed light on some of them, in order to clarify the link between a weak ontology and narrative ethics. The following list includes the fundamental traits (or "existential realities," or "universals") of what it means to be human according to the "Weak Ontology Thesis:" "language, mortality and finitude, natality or the capacity for radical novelty, and the articulation of some ultimate background source" (White 2005, 17).

Taylor himself comments on White's proposal as follows: “our philosophical anthropology takes 'bets' on human constants, but these can only become evident to us by our making sense of human action, passion, and feeling in particular cultural contexts" (Taylor 2005, 40). He substitutes the term "ontology" with the expression "philosophical anthropology” and it is clear that he grounds his philosophical anthropology on "our making sense.” 
Among the declinations of weak ontology, we could enumerate to some extent the narrative interpretation of the self; its ontological presuppositions are shared by Taylor himself inasmuch as he links strong evaluations and narratives together; because strong evaluations are the ontologically specific feature of human beings, narratives tell us something about our personal ontology. Narratives are a very fitting medium to configure and communicate strong evaluations, to interpret moral experiences and configure them, to imagine possible courses of action, to guide the transition from implicit and explicit assumptions, to articulate them as part of our identity; they reflect our images of our lives as a whole, as a story; they are able to explain moral paradigm shifts.

Most importantly, narratives and their supposed capacity to grasp a meaning in our lives are the most useful means to represent our quality of "self-interpreting animals." By what other means could we represent our striving for a sense or a meaning if not by narratives that, in an analogous way, strive for sense and meaning? Human ways of sense-making, of interpreting, are narratively articulated, they proceed narratively, so I will consider self-interpretation as a synonym of self-narration. The point here is double-sided: We could ask ourselves whether this capacity for interpreting or narrating is really so essential or, in other words, whether it is an ontological endowment available to each and every human being. Secondly, it should be clarified whether the meaning is already there, with narratives helping human beings to unfold it, if the meaning is constructed a posteriori, and, finally if it is intrinsic to the narrative forms to the extent that an ending generally coincides with the meaning of a story. In particular, in the first case, narratives would help people to discover a meaning, an always already there "horizon of significance" that they share with other human beings.

This is the reason why in the second part and in my second point, I seek to position the move towards narrative ethics in relation to an implicit ontology. Here I assume a definition of "narrative ethics" as follows: "Narrative ethics explores the intersections between the domain of stories and storytelling and that of moral values as an integral part of stories and storytelling because narratives themselves implicitly or explicitly ask the question: 'How should one think, judge, and act—as author, narrator, character, or audience—-for the greater good?'” (Phelan 2013). Some features are to be underlined in this definition: (a) the relation to value; (b) the fact that narratives help us in our work of articulation and interpretation of what to do and how to act. These two features are doubtlessly endorsed by Taylor himself, who adds to them a fundamental reference to ontology, or philosophical anthropology: humans' constant attitude to make sense through stories implies the ontological commitment that makes the work of interpretation a defining feature of human beings.

In "Ethics and Ontology," Taylor recognizes that man's own way of life "consists of ways of sense making” (Taylor 2003, 314): This human trait is thus an ontological presupposition, or pre-understanding, in which its objective correlate, i.e., the narration of each individual life experience, inevitably cannot be expressed except as a product automatically endowed with meaning. ${ }^{1}$ The deep-seated reason for such an expression can be found by extending our outlook towards the various proposals offered by narrative ethics. Indeed, it can be noted that the implicit ontological presupposition that defines man as a meaning-making being runs the risk of being accepted unquestioningly as an automatism traceable to the so-called "pre-narrative quality of human experience,” to which Paul Ricoeur, ${ }^{2}$ amongst others, refers. Here, I would like to put forward the hypothesis that this pre-narrative quality is an ex ante projection of the work of meaning-making that generally comes about ex post and, above all, is not within everybody's grasp. This would be an unwarranted ontologization of features of human moral experience (goal-seeking; the structural opening known as intentionality; the aspiration towards a goal that gives a life a sense of accomplishment). 
When it comes to defining a set of anthropological constants, as Taylor notes, it is difficult not to disagree and debate. My objection to the ontological quality of our being narrative animals could be read just as an example of such a difficulty. What is more puzzling is not only the fact that meaning-making may be an ex-post feature, whereas Taylor uses this feature in order to define human beings: Proofs pro or contra this view could be brought about, and this means that such feature is a contingent one, not a necessary one. To try to act morally of course means to come to terms with our capacity for interpreting and being strong evaluators; nevertheless, to be able to act morally must not be taken for granted, by means of an ontologization of such a feature. What is more puzzling, then, is also the fact that the capacity for meaning making (or finding, or discovering...) is not available to all. If it is necessary to revise the fact/value dichotomy by means of a moral phenomenology, perhaps it is just as necessary to connect ethics and ontology differently, trying to look for some anthropological constants that take the centrality of striving for sense and significance into account without guaranteeing positive results. Not even the capacity to raise significant and meaningful questions based on human experience can be said to be universal. "Our representation of ourselves and our experience is constitutive of what we are, and therefore cannot be considered as merely a view on reality, separable from reality, nor as an epiphenomenon, which can be by-passed in our understanding of reality” (Taylor 1985, 47).

The narrative/interpretive articulation of moral experiences is thus, according to Taylor, part of our in-the-world-being; it is constitutive and real; it is similar to the eyes through which we look at the world, a standpoint.

The notion of self-interpretation/representation of the self is analogous to the "pre-narrative quality" of human experience: Both have something to do with the basic structure of human life. If we ascribe a pre-narrative quality or a work of interpretation to human life itself, we run the risk of taking the presence of a significance for granted, since according to this view we only have to read correctly something that is already there. This would be our peculiar task as human beings who have a definite place in an ordered world. An ontology imagined this way is very close to classical ontological patterns and their comforting predilection for teleology.

Concluding this second part, the following issues can be highlighted:

(1) The theories that underline the fundamentality of self-interpretation and narrativity in the constitution of the self, as Taylor's theory of man as self-interpreting animal, presuppose a sort of "weak ontology;"

(2) Their "weakness" notwithstanding, these theories imply some ontological commitments, in particular they ascribe an innate and universal capacity for grasping, finding and unfolding the meaning of life, taking for granted that such a significance exists and that human beings are structurally devoted to understanding and grasping it;

(3) The link between ontology and ethics looks rather like a perfect correspondence: Ontology is ethics, since man's supposed constitutive inclination for a work of interpretation or articulation of our moral experience is exactly what qualifies man as a human being; this opens up some questions related to the fact/value dichotomy and to the naturalistic fallacy;

(4) Narrative ethics has its centrality in human experience and reveals an ontological commitment, probably a weak one, but one that does not mortify human freedom and the risks it carries, only if it is seen as a task, as an endeavour. 


\section{Towards a Different Ontology}

This last point allows for the transition to the third and final part of this contribution. As a matter of fact, in this third part, I will attempt to clarify that the organization of the relationship between ontology and ethics within the perspective of narrative ethics does not mean doing away with the ontological dimension. On the contrary, it must presuppose an ontological background which, however, cannot be identified only in the search for and making of meaning and sense, since this characteristic cannot be said to be universal. It is instead an ability that must be acquired, not one to be taken for granted. Indeed, the ontological background of narrative ethics may be traced from a phenomenology of fragility, exposure, and interdependence: These experiences seem to be much more universal, much more constant than the reflective experiences through which we re-live our experiences in search of meaning. From a phenomenological viewpoint, experiences of loss of significance, of pain, and of complete absence of moral competences and reasoning are more frequent than the experiences through which we can recognize ourselves as self-interpreting animals who thematize such reflections in narrative ways.

Once the fundamental role that narratives and stories play in our relation to moral values has been established, narrative ethics can be anchored to an ontology—not by ascribing an equal inclination to the recognition of a significance in every man, but rather in that narrative ethics reveals its connection with an ontology that recognizes another set of features as defining human beings.

These three explanations and one premise demonstrate that an ethics that finds its application in narrative can be linked to ontology only inasmuch as: The premise is set out as follows—ontological features are actually signs of an ontological condition, so I propose to substitute features with conditions. Let us move to the three explanations:

(1) The discovery of fragility implies a narrative thematization. Fragility is more of an ontological condition than self-interpretation is. By "fragility" I mean a concept that goes together with "vulnerability," taking my cue from Judith Butler. ${ }^{3}$ Narrativity may become the means through which human beings come to terms with the ontological condition of fragility, since narrative competences, once acquired, can help man to reflect ex post on the significance of life or to make ethical choices using moral imagination to think possible courses of action. This point could be referred to the inner life;

(2) "Exposure" evokes unconditional listening. Exposure is an ontological condition. I borrow the term "exposure" from Judith Butler, ${ }^{4}$ who ascribes this feature to bodies faced with the violence of political power, and aim to extend this characteristic to the human condition in general as a means of underlining its precariousness, something that can be shared by humans through narration, by invoking someone to listen to men's stories of exposure. Unconditional listening is the ethical response to an ontological condition, in the same way as narrative thematization, is the human response to the discovery of fragility/vulnerability. Moreover, unconditional listening resembles Taylor's recognition that to be moral agents means also to recognize oneself to be "called upon," in the sense that Emmanuel Levinas ${ }^{5}$ has admirably explained.

(3) Another ontological condition to be recognized as defining human beings is interdependence as the inescapable and even unchosen relevance of the others. From an ethical viewpoint, the recognition of such a condition implies the attempt to transform this condition into an ethical task, one that can be described as a common construction of sense and meaning, even of shared values, through narratives or narrative patterns, since narrative reasoning is much more accessible and in this sense more universal than strictly argumentative reasoning. 
In each of these three points, narrative is recognized to have an ethical import also because it is useful in emancipatory processes that should be able to transform the ontological conditions of fragility, exposure, and interconnectedness into as many occasions of commonality and solidarity. This is a feature that elevates and corroborates the ethical sides of narrative. The emancipatory reach of narrative has to accommodate the possibility of failure of meaning, so that man as a "self-interpreting animal" can become an anthropological objective to aspire to, not an ontologically and immediately acquired given. The definition of man as a self-interpreting animal should therefore be delineated in the sense of an endeavour, so that each individual can build up his own mediated relation with meaning, rendering self-narrative a practice available to all.

Concluding, it seems to me that at least two questions are still not answered in my account: (a) whether or not the three explanations succeed in avoiding a naturalistic explanation, one which would ultimately lead us to recognize in such a description of our ontological conditions just as many natural endowments with which man must come to terms with through ethics in order to survive; (b) why and how human beings can be able or are free to transform an ontological condition into an ethical choice.

\section{Notes}

1. See Taylor, Charles. The Language Animal. Cambridge (MA): Harvard University Press, 2016.

2. Ricoeur, Paul. "Life in Quest of Narrative.” Ed. David Wood. On Paul Ricoeur. Narrative and Interpretation. New York: Routldedge, 1991. 20-33; 29.

3. See Butler, Judith. "Precarious Life, Vulnerability, and the Ethics of Cohabitation.” The Journal of Speculative Philosophy 26.2 (2012): 134-51.

4. See Butler, Judith. Precarious Life: The Powers of Mourning and Violence. London-New York: Verso, 2004.

5. See Levinas, Emmanuel. Otherwise than Being or beyond Essence. Dordrecht: Kluwer, 1991.

\section{Works Cited}

Butler, Judith. Precarious Life: The Powers of Mourning and Violence. London-New York: Verso, 2004.

---. "Precarious Life, Vulnerability, and the Ethics of Cohabitation.” The Journal of Speculative Philosophy 26.2 (2012): 134-51.

Levinas, Emmanuel. Otherwise than Being or beyond Essence. Dordrecht: Kluwer, 1991.

Ricoeur, Paul. "Life in Quest of Narrative.” Ed. David Wood. On Paul Ricoeur. Narrative and Interpretation. New York: Routldedge, 1991. 20-33; 29.

Taylor, Charles. “Ontology.” Philosophy 129.34 (1959): 125-41.

---. “Self-interpreting Animals.” Ed. Charles Taylor. Philosophical Papers. Vol. 1. Human Agency and Language. Cambridge: Cambridge University Press, 1985. 45-76.

---. “Explanation and Practical Reason.” Ed. Charles Taylor. Philosophical Arguments. Cambridge (MA): Harvard University Press, 1995. 34-60.

---. “Ethics and Ontology.” The Journal of Philosophy 100.3 (2003): 305-20.

---. “The 'Weak Ontology’ Thesis.” The Hedgehog Review 7.2 (2005): 35-42.

White, Stephen K. “Weak Ontology.” The Hedgehog Review 7.2 (2005): 11-25. 